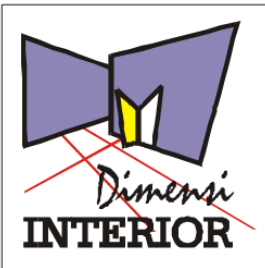

http://dimensiinterior.petra.ac.id

\title{
Upcycle Limbah Kayu Palet Jati Belanda Menjadi Wadah Modular Serbaguna untuk Anak-Anak (Studi Kasus: Kota Surabaya)
}

\author{
Jessica Sutanto $^{1} \mid$ Cok Gede $^{2}{ }^{2}$ Purnama E.D. Tedjokoesoemo ${ }^{1}$ \\ ${ }^{1}$ Program Studi Desain Interior, Universitas Kristen Petra, Surabaya \\ ${ }^{2}$ Program Studi Desain Interior, Institut Seni Indonesia, Denpasar \\ Email: jeesutanto@gmail.com
}

\begin{abstract}
ABSTRAK
Anak-anak memiliki kebutuhan yang terus meningkat seperti buku, baju, dan sepatu. Kebutuhan yang berbeda dari setiap anak menyebabkan wadah yang sifatnya dapat ditambahkan sesuai kebutuhan serta memiliki fleksibilitas yang tinggi dapat dilihat sebagai solusi yang tepat. Momot sebagai wadah modular dengan memanfaatkan limbah palet Jati Belanda dihadirkan sebagai solusi atas masalah di atas. Kayu palet Jati Belanda memiliki carbon footprint lebih kecil dibanding dengan material lainnya seperti, plastik, logam, dan beton sehingga limbahnya dapat dimanfaatkan kembali tanpa merugikan lingkungan. Selain itu, sosialisasi green lifestyle dapat dimulai dari usia dini yaitu, usia 6-12 tahun agar anak menjadi lebih peka dan bertanggung jawab terhadap lingkungan. Pendekatan pemanfaatan limbah yang digunakan dalam perancangan ini adalah upcycle. Proses perancangannya menggunakan metode kualitatif yang berlangsung dalam enam tahap yaitu, discovery -interpretation - ideation - experimentation evolution - implementation. Perancangan mebel knockdown ini dibuat dalam bentuk modular dengan sambungan dasar mortise dan tenon.
\end{abstract}

Kata Kunci: Kayu Palet, Modular, Wadah, Upcycle

\section{ABSTRACT}

Children have increasing needs such as books, clothes, and shoes. Thus, a container that can be added as needed and have high flexibility can be seen as the right solution. Momot as a modular container by utilizing waste wood palette is the solution to the problem mentioned. Wood pallets have a smaller carbon footprint than other materials such as, plastics, metals, and concrete so that the waste can be reused without harming the environment. In addition, to socialize green lifestyle can be started from the early age 6-12 years old. So that children become more sensitive and responsible to the environment.Waste utilization approach used in this design is upcycle. The design process uses qualitative methods that take place in six stages, discovery -interpretation - ideation - experimentation - evolution - implementation. The design of this knockdown furniture is made in modular shape with basic connection of mortise and tenon.

Keywords: Pallete wood, Modular, Shelf, Upcycle

\section{PENDAHULUAN}

Anak-anak pada usia 6-12 tahun mengalami masa pertumbuhan baik fisik, emosional, maupun moral, memiliki rasa keingintahuan dan kreatifitas yang tinggi. Anak- anak cenderung bermain di luar rumah kemudian menyimpan benda-benda menarik yang mereka jumpai di luar yang mereka anggap sebagai harta karun untuk disimpan di ruang pribadi mereka, yaitu kamar tidur. Pada usia 6 tahun anak-anak memasuki Sekolah Dasar (SD) dan mulai memiliki kumpulan buku dan hasil karya yang mereka buat sendiri. Selama periode tersebut, jumlah buku, mainan, karya, dan benda-benda lainnya juga akan meningkat sehingga memerlukan wadah/ rak lebih lagi yang dapat digunakan untuk menyimpan benda-benda tersebut. Wadah/rak yang dapat digunakan untuk lebih dari 1 kegunaan akan memudahkan anak-anak dalam menata, memajang, dan menemukan barang-barang mereka.

Oleh karena itu, anak-anak memerlukan wadah modular serbaguna yang dapat disesuaikan sesuai dengan kebutuhan mereka yang terus meningkat. Bentukan modular yang dapat menciptakan pattern tertentu akan menarik bagi anak-anak pada usia tersebut. Selain itu, dengan adanya wadah serbaguna modular, anak-anak dapat belajar lebih lagi mengenai konstruksi dan permainan bentuk.

Sebagai bentuk partisipasi terhadap green design, dimanfaatkan sebagai material utama wadah modular 
serbaguna karena jejak karbonnya yang rendah dan ramah lingkungan. Di Kota Surabaya, limbah palet Jati Belanda mudah dijumpai dan jumlahnya relatif banyak sehingga harus dimanfaatkan lebih lagi.

Upcycle merupakan prinsip yang tepat untuk digunakan dalam pengolahan palet jati belanda. William McDonough dan Michael Braungart upcycle menggunakan cara re-design bukan menghancurkan atau menghilangkan limbah dengan cara lainnya agar material bekas dapat terus dimanfaatkan secara aman [1]. Selain itu, finishing yang tergolong dalam prinsip upcycle adalah finishing yang tidak mengandung racun dan senyawa kimia yang berbahaya sehingga cocok untuk diterapkan dalam perabot anak.

\section{METODE PERANCANGAN}

Metode analisa yang digunakan dalam perancangan ini adalah metode design thinking. Salah satu design thinking yang diadaptasi dari dari dua literatur yang kemudian dikembangkan oleh perancang sesuai keadaan dan kebutuhan dengan tahapan sebagai berikut [2], [3]:

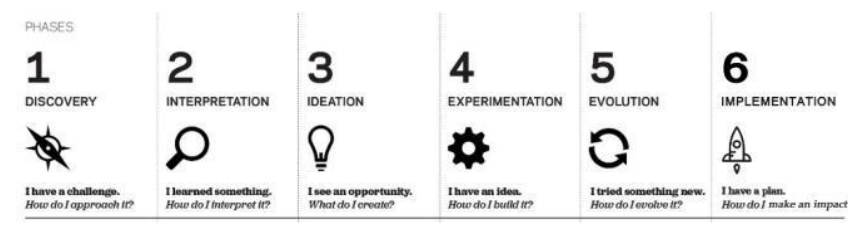

Gambar 1. Rencana metode analisa data

\section{Discovery}

Proses perancangan dimulai dari membuat pertanyaan- pertanyaan yang akan menjadi pegangan agar tidak keluar dari tujuan perancangan berupa wawancara maupun pengumpulan literatur dari sumber yang terpercaya. Hasil tahap ini berupa analisa teori dan hasil survei lapangan.

\section{Interpretation}

Analisa interpretasi dimaksudkan untuk mengambil benang merah dari analisa pada tahap discovery. Benang merah yang didapat kemudian dibuat kedalam framework.

\section{Ideation}

Analisa ideation memanfaatkan hasil dari tahap sebelumnya untuk membuat alternatif desain wadah modular serbaguna sebanyak mungkin dengan konstruksi sesederhana mungkin terkait limbah yang ada melalui sketsa desain.

\section{Experimentation}

Proses pembuatan eksperimen dibantu oleh tukang, dan selama proses pengerjaannya memungkinkan untuk terjadi perubahan desain. Hasil dari eksperimen di analisa dan di uji coba untuk kemudian kemudian di perbaiki kembali menjadi desain akhir.

\section{Evolution}

Pada tahap evolution, desain yang telah dikembangkan dan sudah melalui tahap experiment dipilih satu untuk diproduksi. Pengembangan desain masih bisa terjadi pada tahap ini.

\section{Implementation}

Tahap implementation bertujuan untuk mempromosikan desain yang telah dibuat. Promosi bisa tercapai melalui pembuatan produk sekunder berupa buku, artikel, brosur, branding ke pasar (Nasional), dan membuat bussiness plan.

\section{KAJIAN TEORI}

\section{A. Anak-Anak}

Anak usia sekolah biasa disebut anak usia pertengahan. Periode usia tengah merupakan periode usia 6-12 tahun [4]. Anak usia sekolah menurut Erikson dalam Wong berada dalam fase industri. Anak mulai mengarahkan energi untuk meningkatkan pengetahuan dari kemampuan yang ada. Anak belajar berkompetisi dan bekerjasama dari aturan yang diberikan. Anak mulai ingin bekerja untuk menghasilkan sesuatu dengan mengembangkan kreativitas, keterampilan, dan keterlibatan dalam pekerjaan yang berguna secara sosial [4], [5].

Petunjuk desain yang diminati anak dengan batasan usia menurut Fishel, yaitu:

I. Usia 6-7 tahun: Kemampuan motorik anak berkembang sehingga anak akan tertarik dengan permainan interlocking blocks, pattern, dan transformable. Anakanak pada usia ini menyukai warna kontras yang cerah.

2. Usia 8-9 tahun: Anak-anak masih menyukai warna cerah dan bentuk pattern.

3. Usia 10-12 tahun: Pada usia ini anak cenderung bermain lebih banyak sehingga mereka akan mudah merasa lelah dan memerlukan waktu istirahat lebih. Oleh karena itu anak-anak usia 10-12 tahun lebih menyukai warna yang dingin atau tenang. Kemampuan berpikir anak juga akan berkembang, sehingga dibuat lebih kompleks.

\section{B. Antropometri}

Kenyamanan suatu perabot bergantung pada antropometri penggunannya (dalam hal ini pengguna adalah anak usia 6-12 tahun). Data antropometri menurut Perhimpunan Ergonomi Indonesia adalah sebagai berikut [6]:

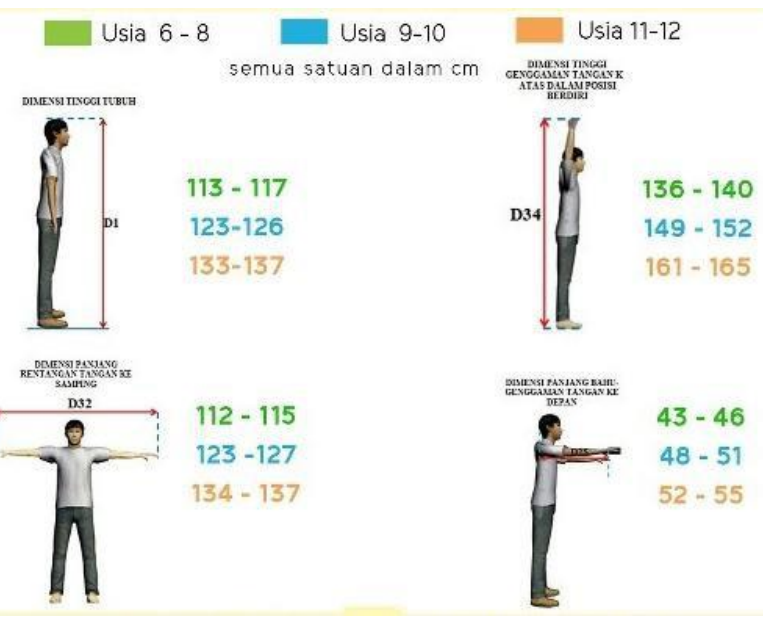

Gambar. 2. Antropometri anak usia 6-12 tahun 


\section{Mebel}

Pengertian mebel secara umum, mebel adalah perabot yang memiliki tempat untuk menyimpan sesuatu dengan posisi tetap atau memiliki tempat tertentu di dalam ruangan dari bahan tertentu yang berdiri sendiri" [7].

Perabot dengan fungsi sebagai tempat menyimpan merupakan kata lain dari gudang bagi barang tertentu yang berukuran relatif kecil. Jenis perabot yang berfungsi sebagai tempat menyimpan sesuatu di dalamnya meliputi lemari, rak dengan laci [7].

\section{Bentuk}

Rupa bentuk yang disarankan untuk anak yaitu rupa bentuk geometris (lingkaran, segitiga dan bujur sangkar) karena rupa bentuk ini mendominasi lingkungan buatan manusia [8]. Selain itu pada usia tersebut, anak-anak tertarik dan diperkenalkan pada bentuk-bentuk geomertis sederhana yang berada disekelilingnya.

Terdapat beberapa makna yang terkandung dalam rupa bentuk segiempat antara lain sebagai berikut [9]:

- Menunjukkan kejernihan dan rasionalitas.

- Keempat sisinya yang sama panjang dan keempat sudutnya yang saling tegak lurus menghasilkan keteraturan dan kejernihan visual.

- Dapat diberi variasi seperti mengubah ukuran, proporsi, warna. Untuk menghindarkan suasana yang monoton.

- Stabil dan tenang jika berdiri pada salah satu sisinya. Menjadi dinamis bila berdiri pada salah satu sudutnya.

- Mudah diukur, digambar, diproduksi dan mudah dapat dicocokan ke dalam konstruksi.

\section{E. Warna}

Jenis warna ini dapat mampu menggali kreativitas mereka. Berikut ini adalah karakter warna terhadap anakanak:

- Wama primer (merah, kuning, biru) memiliki kesan aktif dan dinamis, merangsang kreativitas, meningkatkan rasa ingin tahu dan membuat anak nyaman berada dalam satu ruang.

- Warna pastel (salem, merah muda, hijau pastel) memberi kesan bersih, ringan namun lembut, nyaman dan menenangkan. Kebanyakan warna pastel akan menyebabkan kelesuan dan kehabisan energi dan kemudian membuat anak gelisah dan lekas marah.

- Warna ringan (kuning matahari, hijau rumput, biru awan, dll.) membuat suasana terasa segar dan nyaman.

- Warna natural (terakota, coklat kayu) memberi kesan hangat, dekat dengan alam.

\section{F. Sustainability}

Sustainable design adalah pendekatan desain yang dapat memenuhi kebutuhannya saat ini tanpa berkompromi dengan kesanggupan generasi berikutnya untuk memenuhi kebutuhannya [10]. Desain yang berkelanjutan merupakan desain yang tercipta dengan pertimbangan kekuatan, perawatan, nilai ekonomi dan nilai budaya yang dapat terus berkembang dan terulang dengan harmonis tanpa melupakan keseimbangan alam.

Konsekuensi desain yang menguntungkan ketiga sektor ini adalah dalam hal penciptaan standarisasi yang tepat dalam segala aspek. Desain yang sustainable harus dapat bertahan dan berulang sehingga proses ini dapat menguntungkan semua stakeholders terkait, antara lain:

1. Sosial, berhubungan dengan masyarakat sebagai sumber daya manusia. Desain akan membentuk perilaku di masyarakat yang kemudian membentuk kebiasaan lingkungan dan pada akhirnya menciptakan kebudayaan hidup yang baru.

2. Ekonomi, merupakan aspek penghubung dan dasar dari keberlangsungan suatu sistem perputaran industri dalam dunia.

3. Ekologi, Alam ini harus terjaga dari segi kualitas dan kuantitas agar tercipta keharmonisan yang saling menguntungkan di dunia.

\section{G. Sifat Dasar Material}

Setiap jenis material limbah bekas memiliki sifat alami yang berbeda-beda. Sifat ini bergantung pada asal material dan sistem produksinya dalam industri. Sifat-sifat material ini dapat dikategorikan berdasarkan sifat fisiknya dan sifatnya setelah mengalami perubahan dalam waktu dan kondisi lingkungan.

Material bekas yang akan diletili adalah palet kayu jati belanda karena ketersediaannya yang relatif cukup banyak di pasaran. Selain itu, jejak karbon (carbon footprint) yang dimiliki kayu juga lebih kecil (hampir 0) dibanding dengan material lainnya sehingga cocok untuk di upcycle. Menurut Abbott 'A 'carbon footprint' is a measure of the greenhouse gas emissions associated with an activity, group of activities or a product. " [11].

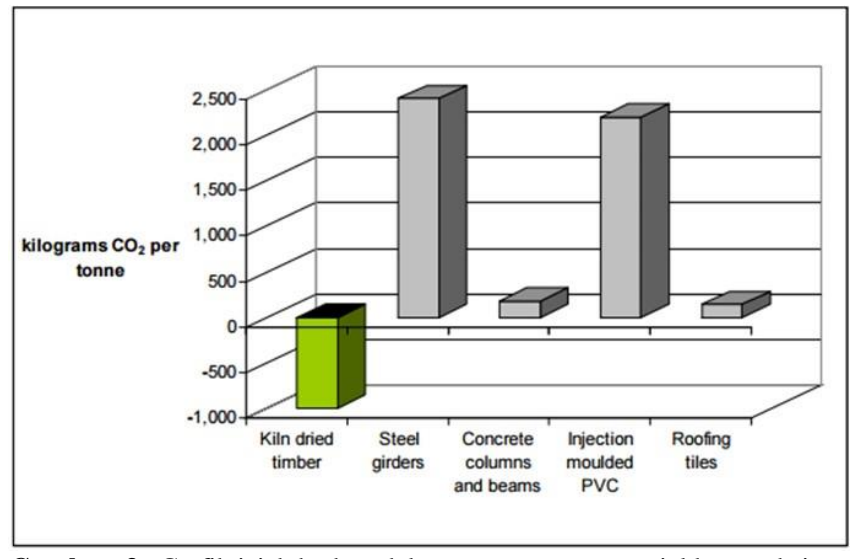

Gambar. 3. Grafik jejak karbon dalam penggunaan material konstruksi (kiri-jejak karbon kayu)

Jika kayu dikirim ke TPA, kayu akan terurai dan menghasilkan metana (gas rumah kaca). Namun, hanya sebagian kecil dari kayu di TPA yang terurai dan menghasilkan metana, sedangkan sisanya tetap berada di tanah sebagai penyimpan karbon. Jadi jauh lebih baik untuk mendaur ulang limbah kayu dengan membuatnya menjadi produk lain. Akhirnya, jika tidak bisa lagi didaur ulang, kayu dapat dibakar untuk pemulihan energi, yang dapat memiliki manfaat tambahan menggusur bahan bakar fosil yang mungkin telah digunakan. Hasil pembakaran kayu yang tidak terkontaminasi juga bisa kembali ke tanah sebagai nutrisi atau bisa disebut sebagai nutrisi biologis. Jika sudah melalui tahap ini, proses daur ulang kayu bisa disebut upcycle [1]. 


\section{H. Bahan: Kayu Palet Jati Belanda}

1. Karakter

Kayu Jati Belanda atau atau istilah Jawanya disebut jati londo sebenarnya merupakan kayu Pinus atau pinewood banyak digunakan di berbagai belahan dunia karena memiliki serat atau corak tekstur kayu yang sangat bagus dan memiliki permukaan serat yang halus. Di Indonesia sendiri kayu ini di kenal dengan kayu Jati Belanda atau kayu jati londo atau kayu palet bekas peti kemas.

Secara fisik karakternya lebih empuk dan lebih cerah warnanya. Dikarenakan tingkat kekerasan kayu yang tidak begitu keras maka pengolahan kayu ini menjadi relatif mudah dan disenangi oleh para pengrajin. Kayu ini memiliki serat yang indah dan sangat menonjol motifnya dibanding kayu- kayu jenis lain. Jenis kayu ini juga tahan dari rayap karena getahnya tidak disukai serangga, biasanya digunakan untuk bahan dasar pewangi/antiseptik kamar mandi seperti densol.

Beberapa kayu diantaranya juga dioven untuk memenuhi standar pengemasan barang-barang impor, sesuai standar luar negeri (Jerman atau Jepang), sehingga kayu ini menjadi kuat dan ringan cocok untuk furnitur [12].

\section{Dimensi}

Dimensi standar palet kayu jati belanda sebagai berikut:

- Spesifikasi 1 (panjang $100 \mathrm{~cm} \times$ lebar $100 \mathrm{~cm} \times$ tinggi $14 \mathrm{~cm})$

- Spesifikasi 2 (panjang $115 \mathrm{~cm}$ x lebar $115 \mathrm{~cm} \times$ tinggi $14 \mathrm{~cm})$

- Spesifikasi 3 (panjang $120 \mathrm{~cm} \times$ lebar $110 \mathrm{~cm} \times$ tinggi $14 \mathrm{~cm})$

\section{Pendekatan Pemanfaatan Limbah: Upcycle}

Menurut William McDonough dan Michael Braungart, redesign merupakan cara yang dipilih untuk diterapkan dalam upcycle, bukan menghancurkan atau menghilangkan limbah dengan cara yang lain [1].

Tujuan dari upcycle adalah keberagaman yang menyenangkan, aman, sehat, dan hanya dunia dengan udara, air, tanah yang bersih, dan perekonomian yang merata, ekologis, dan dapat dinikmati. Dalam prinsipnya, upcycle mengajak untuk berpikir bahwa semua limbah bisa menjadi nutrisi.

Untuk mencapai tujuan, maka dalam proses upcycle tidak disarankan untuk mencampur beberapa material, seperti mebel yang mengandung lem, bahan kimia, dan senyawa lain, karena produk yang sudah mengandung beberapa material itu akan kehilangan potensi untuk digunakan sebagai produk berulang dalam jangka waktu yang panjang. Dengan cara yang demikian, lapangan kerja baru akan muncul lebih banyak lagi. Segala perubahan yang tidak terkontaminasi, apapun bentuk produknya nanti, akan tetap disebut upcycle.

\section{J. Finishing}

Proses finishing kayu jati belanda pada dasarnya sama dengan finishing kayu jenis lainnya. Namun demikian, proses finishing tersebut harus bisa menutupi kekurangan kayu ini yang cenderung tidak rapat dan rentan terhadap air. Produk finishing yang digunakan haruslah yang bisa memberikan lapisan perlindungan yang benar-benar baik.

Produk yang dipilih sebaiknya datang dari seri cat water based yang memiliki water resistance baik [13]. Cat water based umumnya memiliki kandungan VOC dibawah ambang batas yang ditentukan. Cat berpelarut air juga terbebas dari bahan beracun [14].

\section{K. Konstruksi \\ 1. Modular}

Menurut Muharam arti dari kata modular adalah memiliki kemampuan untuk dipindahkan dengan mudah dan umumnya berdiri sendiri dalam bentuk modul yang dapat dipisah- pisahkan [15].

Modular memiliki bentuk yang efisien (mudah di bongkar pasang dan diangkut) dan bahan yang sustainable (dapat digunakan berulang). Modular umumnya dapat berdiri sendiri dan dapat dibangun secara terpisah dimana perubahan satu modul akan berdampak pada modul yang lain dan bentuk secara keseluruhan.

\section{Knockdown}

Knockdown bisa juga dikenal sebagai sistem bongkar pasang. Mebel dengan sistem ini biasanya membutuhkan perakitan lagi setelah di beli. Knockdown furniture terdiri dari bagian datar, pengencang, dan penguat. Kekuatan sistem ini terletak pada sambungan. Sambungan sebagian besar terbuat dari baut atau sekrup, beberapa menggunakan jointer lainnya untuk merekatkan komponen antar bagiannya.

\section{DESKRIPSI OBYEK PERANCANGAN DAN PROGRAM RUANG}

\section{A. Deskripsi Obyek Perancangan}

Perancangan wadah modular serbaguna dari limbah kayu palet Jati Belanda untuk anak-anak usia 6-12 tahun dibuat modular dengan sistem knock-down sederhana sehingga anak- anak bisa berpartisipasi dalam perakitan perabot yang akan mereka gunakan. Bentuk yang digunakan juga terbatas pada bentuk geometris sederhana agar mudah untuk dikombinasikan.

Produk ini memiliki fungsi utama yaitu sebagai wadah serbaguna (buku, sepatu, mainan, dan baju) yang tidak berhubungan langsung dengan aktivitas manusia. Produk ini terdiri dari modul utama dan modul pendukung yang akan dipasarkan ke dalam 3 bentuk.

\section{B. Analisa Kebutuhan}

Analisa kebutuhan diperoleh dari hasil wawancara dengan hasil sebagai berikut:

1. Rak yang dibutuhkan anak adalah rak buku, rak sepatu, box mainan, rak baju.

2. Rak dan perabot anak $90 \%$ berada di dalam kamar anak (10\% menjawab rak sepatu berada di luar kamar).

3. Penambahan rak dan perabot biasa terjadi di usia 6 tahun (peralihan dari TK ke SD) dan di usia 8-9 karena koleksi buku, dll bertambah).

4. Selama usia 6-12, 78\% responden mengatakan bahwa kebutuhan rak dan perabot tidak pernah diganti malah semakin bertambah dan tidak akan. Sedangkan 22\% mengatakan sudah berganti karena rusak. 
5. Rak dan perabot tidak diganti kecuali sudah rusak.

\section{Batasan Desain}

1. Customer Segmentation

- User: Anak-anak usia 6-12 tahun, laki-laki dan perempuan

- Marketing: Online melalui media sosial dan Bazar

- Region : Nasional

2. Buying Situation

- Buyer: Orang Tua

- Sales : Per set(isi standar), per modul (terpisah)

3. Fungsi

Sebagai wadah serbaguna, yang tidak berhubungan langsung dengan aktivitas manusia. Rak buku, sepatu, mainan, baju, dll.

4. Konstruksi

- Modular - bentuk bervariasi

- Knock-down - sistem bongkar pasang

5. Ukuran

Ukuran maksimal tiap modul adalah 110 x 40 x $110 \mathrm{~cm}$ (panjang x lebar x tinggi)

\section{KONSEP PERANCANGAN}

\section{A. Kerangka Berpikir}

Konsep perancangan wadah serbaguna adalah "To Be Continue". Dimana arti kata "continued" menurut Merriam- Webster adalah lasting or happening for a long time without interruption. Sedangkan "to be continued" dalam Longman berarti used at the end of part of a story, a television show etc to tell people that the story has not finished yet [16].

Jadi konsep ini ingin menjelaskan bahwa desain yang akan dibuat bisa bertahan dan berlanjut menjadi desain dengan bentuk dan fungsi lain yang dapat di tambah sewaktu-waktu sesuai dengan bertambahnya kebutuhan anak.

Kebutuhan anak usia 6-12 tahun seperti buku, baju, sepatu, mainan, dan hasil karya akan semakin bertambah seiring pertambahan usia, oleh karena itu produk ini di desain dengan konsep berkelanjutan agar produk dapat terus dikembangkan dan dikombinasikan untuk menambah besaran dan mengubah bentuk. Dengan adanya produk ini diharapkan limbah palet akan berkurang dan anak-anak bisa merakit perabot mereka sendiri sesuai kreatifitas dan luasan kamar yang mereka tempati.

Selain itu, beberapa modul juga akan dijual secara terpisah agar pembeli yang ingin menambah ukuran maupun bentuk bisa dengan mudah mengkombinasikan dengan produk yang mereka miliki sebelumnya dengan atau tanpa merubah produk yang lama

\section{B. Aplikasi Perancangan}

Konsep desain dibuat berdasarkan latar belakang perancangan, dengan aplikasi sebagai berikut:

a. Warna

Warna yang digunakan merupakan warna ringan yaitu, kuning matahari - biru langit - merah muda - hijau rumput, membuat suasana terasa segar dan nyaman. Dan warna natural kayu agar keindahan serat kayu bisa ter-expose. Anak usia 6-9 tahun memiliki energi yang banyak sehingga warna terang akan membuat mereka lebih bersemangat. Sedangkan anak usia 9-12 tahun memiliki waktu bermain yang banyak dan mudah merasa lelah dan membutuhkan waktu istirahat di kamar, sehingga warna ringan akan membuat ruang terasa nyaman.

b. Bentuk

Bentuk yang digunakan terdiri dari bentuk geometri sederhana seperti segi empat, lingkaran, dan segitiga, agar mudah di kombinasikan dengan bentuk lain karena memiliki permukaan yang sama. Selain itu, anak-anak akan lebih mudah dalam memahami dan mengingat bentuk-bentuk dasar.

c. Material

Limbah palet Jati Belanda digunakan sebagai material utama wadah modular. Limbah ini memiliki warna yang cerah, serat kayu indah, permukaan yang halus. Selain itu harganya lebih murah dibanding kayu keras pada umumnya namun memiliki kualitas tinggi (memiliki standarisasi kekeringan kayu yang juga berstandar internasional), anti rayap karena getahnya tidak disukai serangga atau rayap, dan lebih ringan dibanding kayu keras lainnya.

d. Finishing

Finishing yang dipilih adalah waterbased, karena jenis ini mudah dibersihkan dan aman untuk anak.

e. Tren desain

Tren desain yang dipilih adalah Scandinavian, karena didominasi warna netral, menekankan pada fungsi dan bentuk sederhana, serta eco-friendly.

\section{C.Branding}

Brand dari wadah modular serbaguna ini adalah "MOMOT" yang berasal dari Bahasa Jawa yang artinya "memuat" atau mengakomodasi. Bahasa Jawa digunakan sebagai brand image karena dapat mewakili produk dari segi sumber daya material dan sumber daya manusia, dimana material yang digunakan adalah limbah kayu palet Jati Belanda dari kota Surabaya, Jawa Timur, sedangkan proses produksi juga di kerjakan di Jawa Timur.

\section{MOMOT $\Rightarrow$ MOMOT}

Gambar. 4. Font momot (kiri), logo MOMOT (kanan)

Warna yang digunakan adalah kombinasi warnawarna dasar yang juga digunakan sebagai warna produk dan pattern kayu palet agar masyarakat terutama anakanak mendapat gambaran bahwa produk ini terbuat dari kayu palet. Font yang digunakan dalam logo tidak hanya tebal dan tegas tetapi juga sedikit melengkung di setiap ujung. Tujuannya agar bentuk tulisan dapat dibaca dengan jelas dan bagian ujung melengkung menggambarkan bentuk produk yang tegas (persegi) namun bagian ujung produk tidak tajam (sedikit melengkung) agar aman digunakan oleh anak. Di setiap pertemuan potongan diberi dua garis putih yang menggambarkan penyambung yang digunakan dalam produk, yaitu dowel. 


\section{DESAIN AKHIR}

\section{A. MOMOT seri T}

Seri ini merupakan pengembangan dari desain alternatif 1. Alternatif yang pertama ini terdiri dari 4 modul (A-B-C-D), dimana modul $\mathrm{C}$ terdiri dari 3 palet terpisah yang dipasang secara bersamaan. Modul D merupakan laci yang pemasangannya tidak bisa sembarangan. Saat tidak ada laci di bagian bawah, laci hanya disarankan berada di ketinggian maksimal $60 \mathrm{~cm}$ dari bawah, namun jika pada bagian bawah sudah dipasang laci, maka laci aman di pasang sampai ketinggian $120 \mathrm{~cm}$.

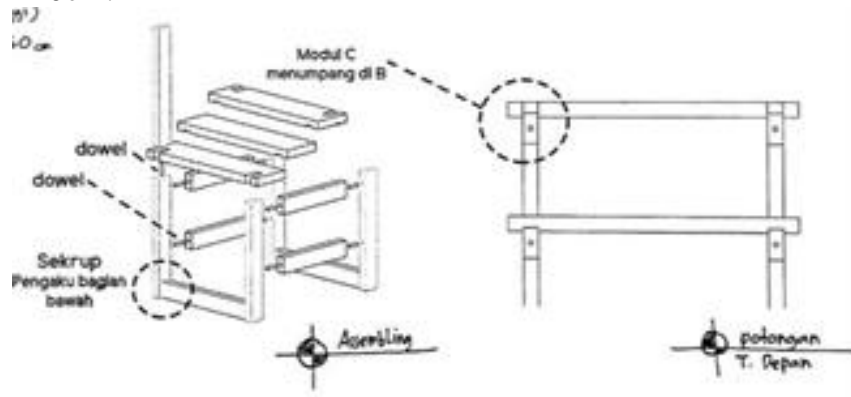

Gambar. 5. Detail konstruksi transformasi desain alternatif 1

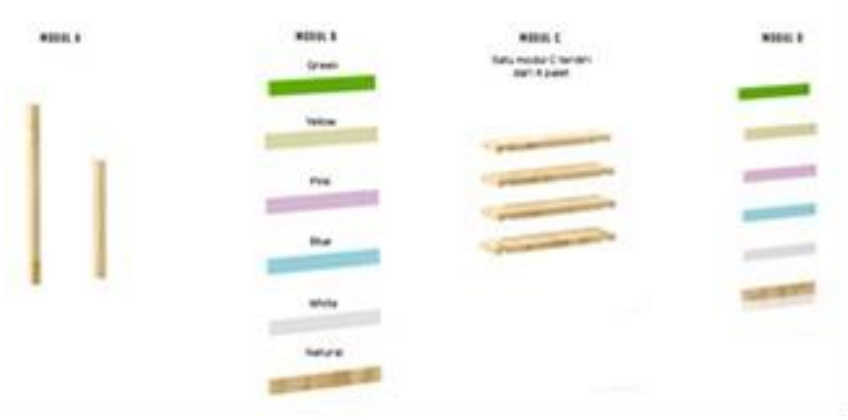

Gambar. 6. Modul-modul MOMOT seri T

Setiap modul terdiri dari 6 warna yang dapat dikombinasikan menjadi banyak konfigurasi. Modul dapat ditambah, dikurang, dan diubah sewaktu-waktu sesuai kebutuhan.
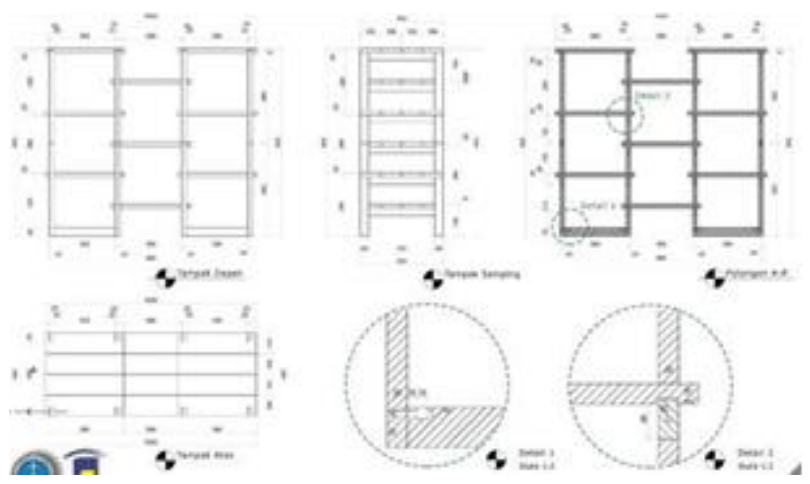

Gambar. 7. Multiview dan detail seri T

Gambar 7 merupakan salah satu contoh tampak depan-samping-atas dari seri T. Pada tampak depan terlihat bahwa antara bidang horisontal satu dengan yang lain tidak bisa di letakkan sejajar atau bersebelahan karena bidang tumpunya hanya ada 1 (detail 2).

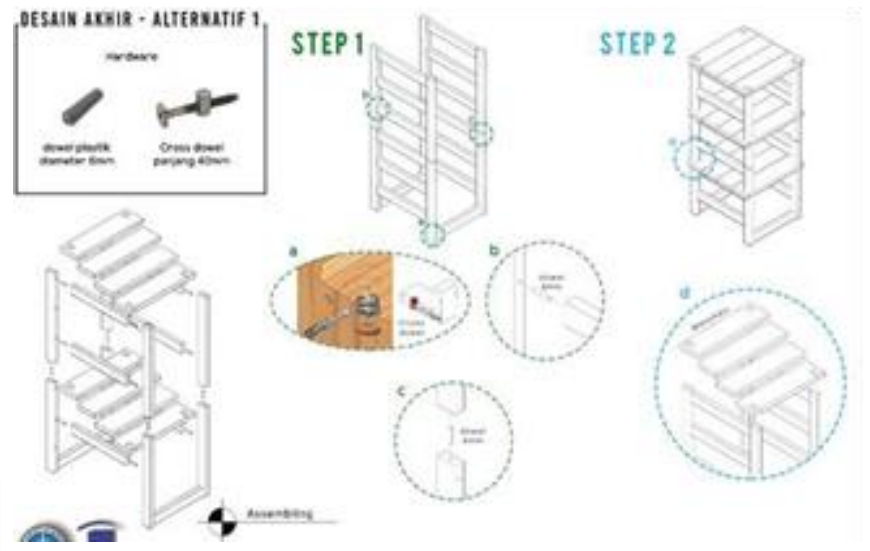

Gambar. 8. Assembling dan instruksi pemasangan

Konstruksi yang digunakan dalam seri $\mathrm{T}$ ini adalah dengan sambungan dowel, cross dowel, dan mortise tenon. Sambungan-sambungan ini adalah sambungan dasar sehingga anak-anak dapat dengan mudah mengerti dan merakit produk dengan bantuan orang tua. Ukuran tiap modul juga tidak lebih dari $45 \mathrm{~cm}$ sehingga tiap modul dapat dijangkau oleh anak- anak.
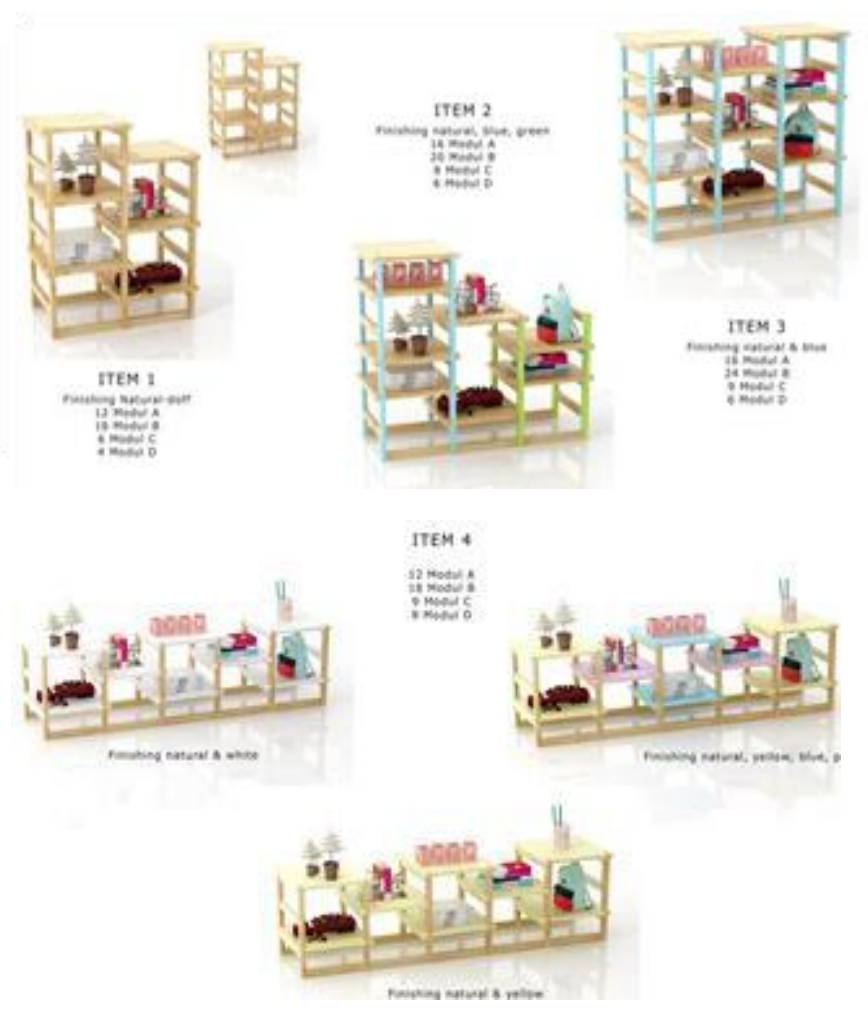

Gambar. 9. Konfigurasi penyusunan MOMOT seri T

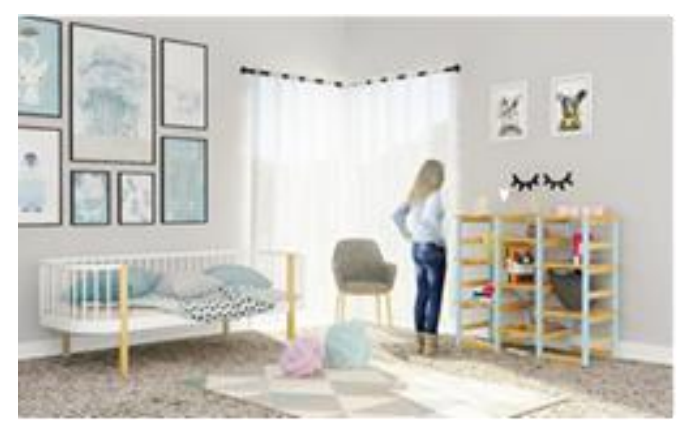

Gambar. 10. Aplikasi MOMOT seri T dalam kamar tidur anak 


\section{B. MOMOT seri M}

Seri ini merupakan pengembangan dari desain alternative 2. Alternatif yang kedua ini terdiri dari 4 modul (A-B-C-D). Modul A terdiri dari 2 ukuran yaitu $30 \mathrm{~cm}$ dan $45 \mathrm{~cm}$ agar dapat menyesuaikan dengan antropometri anak. Alternatif 2 ini hampir sama dengan alternatif 1 , bedanya adalah peletakan modul D pada alternatif ini bisa sejajar/bersebelahan. Untuk menguji kekuatan dari alternatif 1 dan 2, maka alternatif 2 dipilih untuk di produksi sebagai produk uji coba karena desainnya sedikit lebih rumit daripada alternatif 1.

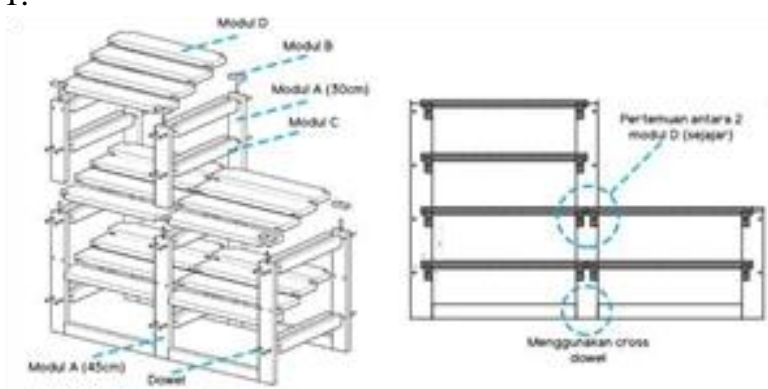

Gambar.11. Detail konstruksi transformasi desain alternatif 2

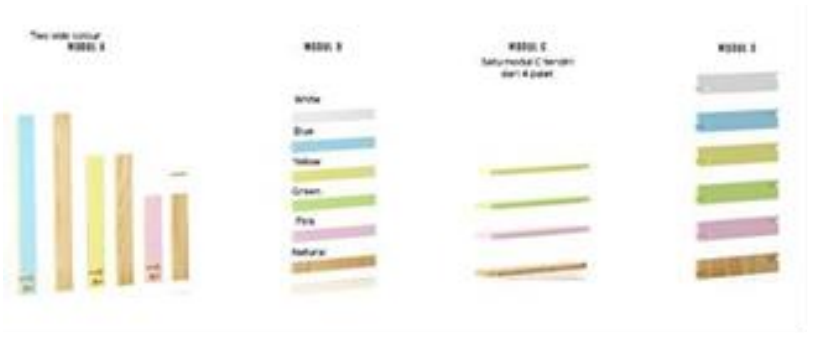

Gambar. 12. Modul-modul MOMOT seri M

Pada seri $\mathrm{M}$ terdapat 4 modul dimana setiap modul terdiri dari enam pilihan warna yaitu, natural - hijau muda - kuning muda - merah muda - biru muda - putih. Pada modul A terdapat 2 warna sekaligus yaitu natural pada sisi depan dan warna pada sisi belakang. Tujuannya agar serat asli dari kayu palet yang indah tetap terekspose karena kecenderungan anak usia 6-12 tahun menyukai segala sesuatu yang berwarna.

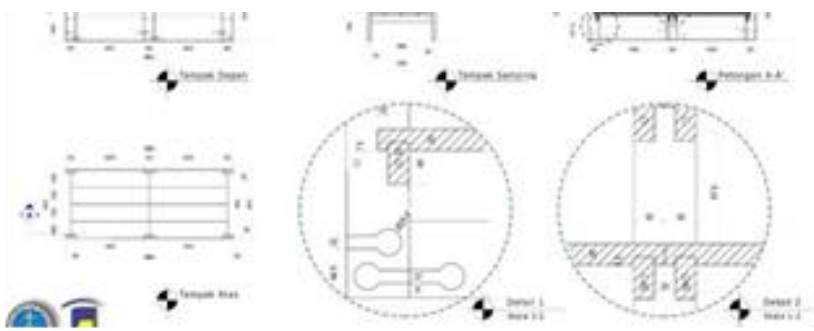

Gambar. 13 Multiview dan detail seri M

MOMOT seri $M$ ini terlihat lebih rapat dan rapi namun akan terkesan kaku jika terdiri dari 1 warna saja. Oleh karena itu, kombinasi warna diperlukan pada seri ini. Kelebihan dari seri $\mathrm{M}$ ini adalah bidang horisontal dapat diletakkan bersebelahan atau sejajar sehingga bidang datar yang terbentuk bisa panjang sesuai kebutuhan

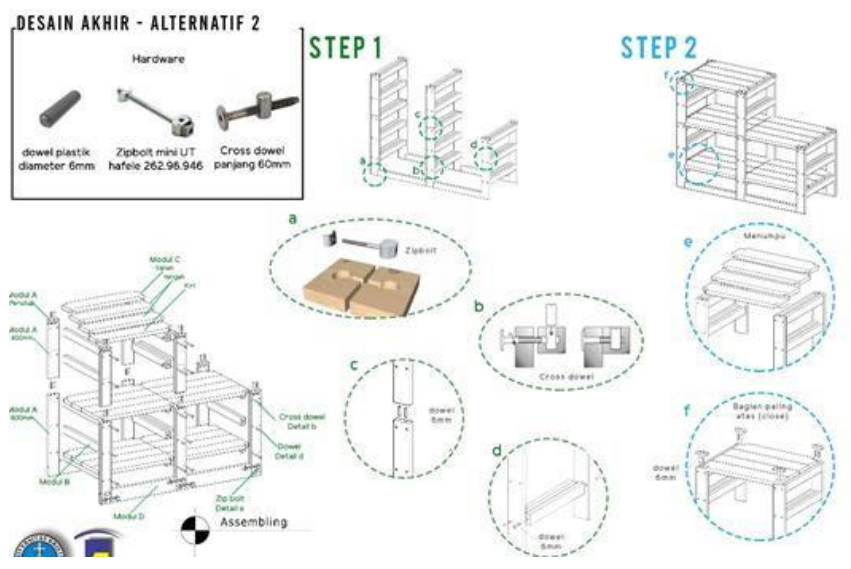

Gambar.14. Assembling dan instruksi pemasangan

Hardware yang digunakan dalam seri ini lebih banyak sehingga sedikit lebih rumit dibanding seri sebelumnya, yaitu dowel, cross dowel, dan zipbolt. Dalam pemasangannya, anak- anak memerlukan bantuan orang tua untuk memahami cara kerja hardware.
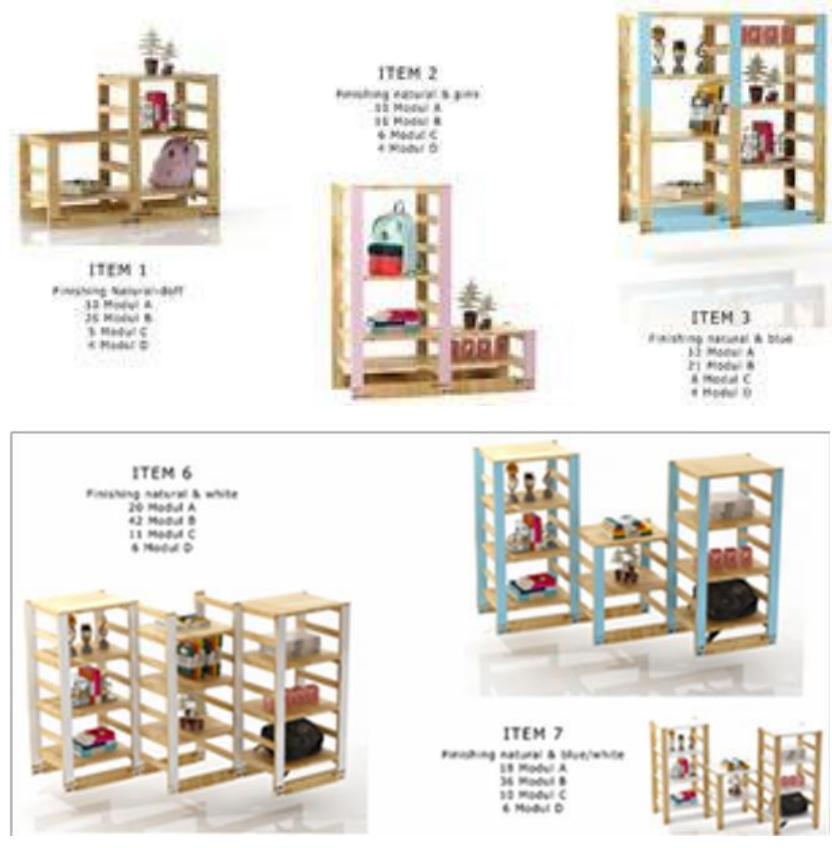

Gambar. 15. Konfigurasi penyusunan MOMOT seri M

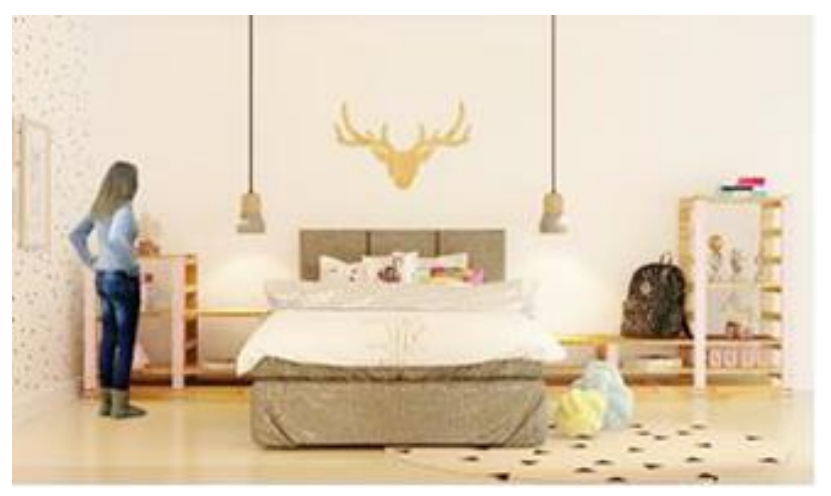

Gambar. 16. Aplikasi MOMOT seri M dalam kamar tidur anak 


\section{MOMOT seri O}

Seri ini merupakan pengembangan dari desain alternative 3. Alternatif ini terdiri dari 3 modul (A-B-C). Modul A dan B yang sudah dirangkai sudah bisa berfungsi sebagai rak, sedangkan modul $\mathrm{C}$ adalah modul tambahan dan tidak berfungsi maksimal tanpa modul B saat dipasang ke modul A. Modul A memiliki beberapa lubang yang digunakan untuk pemasangan dowel plastik, jadi penghubung tiap modul adalah dowel agar dapat dengan mudah dikerjakan anak-anak. Modul B dan C bisa diletakkan dimana saja sesuai keinginan dan sesuai dengan lubang-lubang pada modul A.

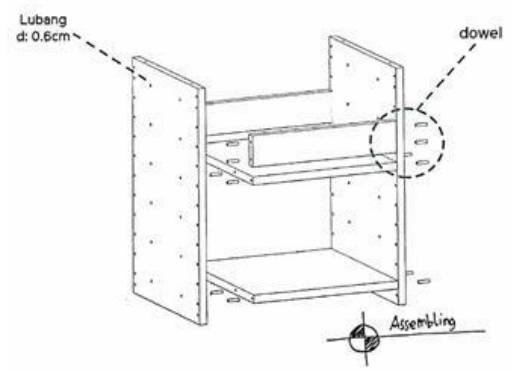

Gambar.17. Detail konstruksi transformasi desain alternatif 3

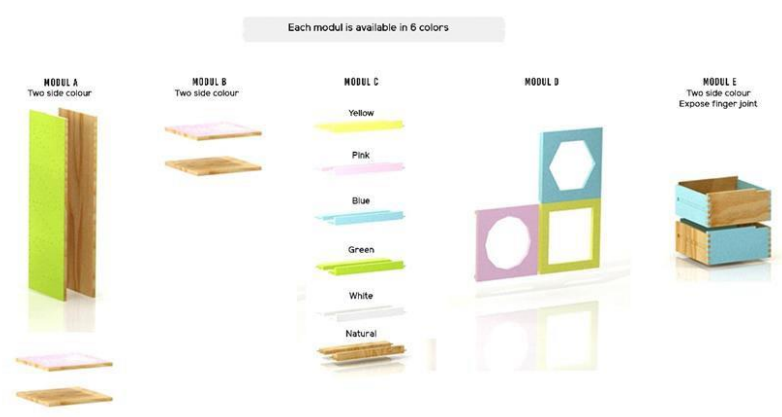

Gambar. 18. Modul-modul MOMOT seri O

Pada seri $\mathrm{O}$ terdapat 5 modul dimana setiap modul terdiri dari enam pilihan warna yaitu, natural - hijau muda - kuning muda - merah muda - biru muda - putih (lihat gambar 22). Finishing yang digunakan adalah cat waterbased "Belazo". Modul A-B-E memiliki 2 warna berbeda pada tiap modulnya yaitu kombinasi natural dan warna. Agar serat alami kayu palet tetap mendominasi dan terekspose. Modul E yang merupakan laci terbuat dari finger joint dimana perpaduan 2 warna berbeda membuat sambungan terlihat sebagai bagian dari estetika.

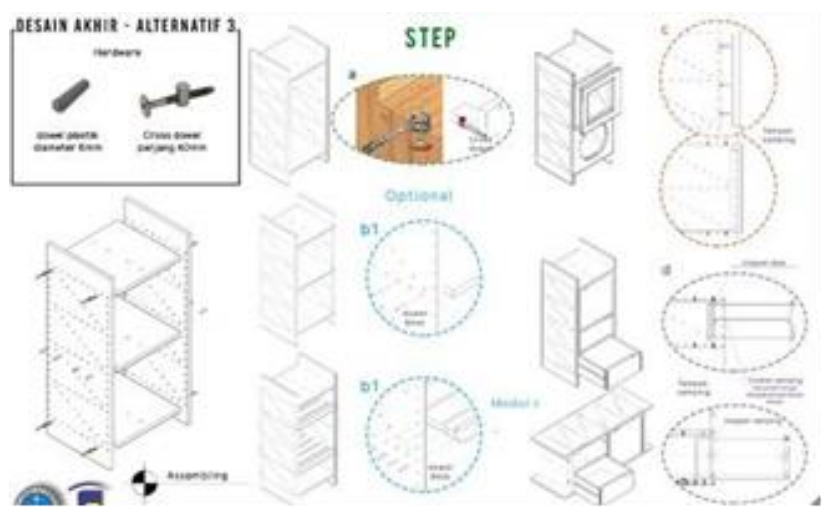

Gambar.19. Assembling dan instruksi pemasangan seri $\mathrm{O}$
Cara pemasangannya juga tergolong mudah, namun anak tetap bisa mengekspresikan kreatifitas mereka dalam produk ini dengan permainan modul. Langkah $d$ menunjukkan bahwa laci tetap memiliki stopper baik dalam posisi berdiri maupun tidur.

Pada seri ini, konfigurasi yang tercipta dapat beragam tergantung jenis modul yang digunakan. Gambar 20 menunjukkan penyusunan MOMOT seri $\mathrm{O}$ modul A-B. Modul A - B merupakan bentukan dasar dari seri $\mathrm{O}$ karena bentuknya sederhana dan pemasangannya lebih mudah.

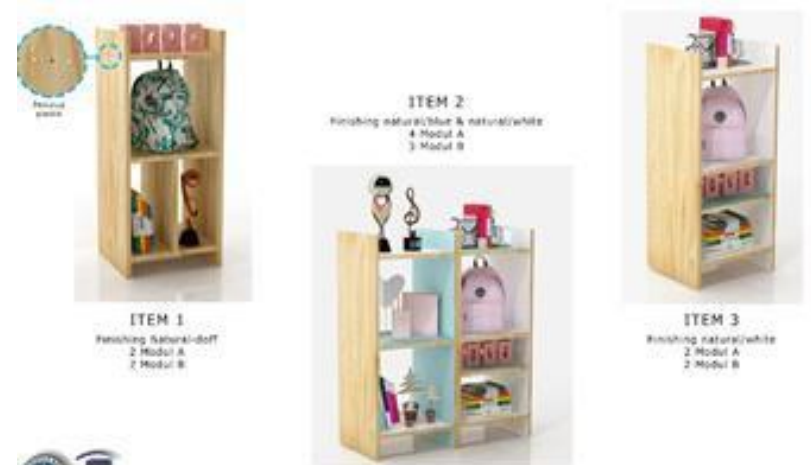

Gambar. 20. Konfigurasi penyusunan MOMOT seri O dengan modul A-B

Susunan lainnya dapat menggunkaan kombinasi modul A-C. Modul A - C seperti yang terlihat pada Gambar 21 memerlukan dowel yang lebih banyak dibanding modul A-B, karena secara visual modul C dibuat menyerupai kayu palet agar ciri khas dari kayu palet tetap terlihat dalam produk. Selain untuk mendisplay buku, rak yang miring juga bisa digunakan untuk meletakkan sepatu. Agar barang-barang tidak mudah jatuh, maka salah satu modul $\mathrm{C}$ dibuat seperti huruf $\mathrm{L}$ yang berfungsi sebagai stopper.

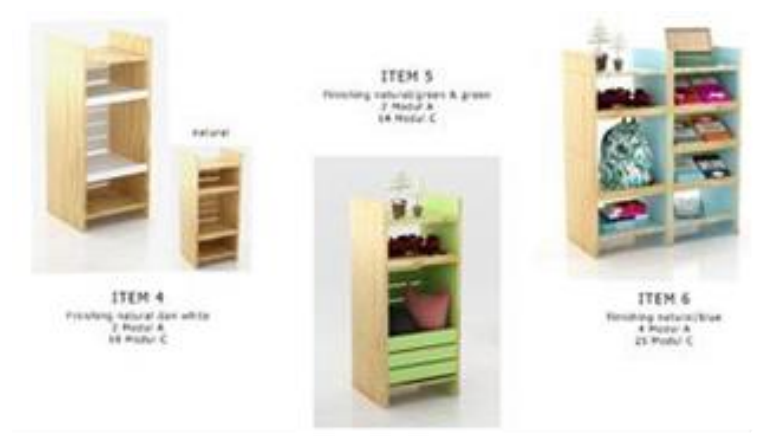

Gambar. 21. Konfigurasi penyusunan seri O dengan modul A-C

Pemasangan modul D sangatlah mudah, hanya tinggal dimasukkan ke modul A seperti tutup (lihat Gambar 19 step C). Modul D merupakan variasi tambahan agar rak tidak terlihat monoton persegi. Selain itu modul D juga berfungsi sebagai frame agar benda di dalamnya tidak mudah jatuh dan terlihat rapi dari luar (lihat Gambar 22 kiri). 


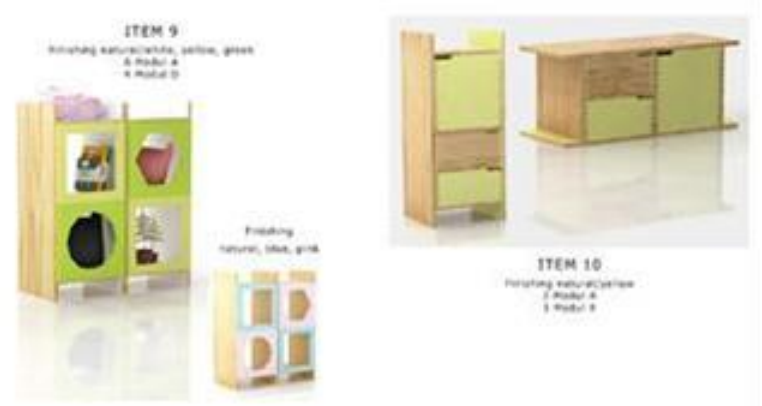

Gambar. 22. Konfigurasi penyusunan seri O dengan modul A-D (kiri) dan modul A-E (kanan)

Modul E berfungsi sebagai laci untuk menyimpan barang- barang pribadi yang tidak ingin diperlihatkan kepada orang lain. Ukuran panjang x lebarnya adalah sama sehingga laci bisa dibuat dalam posisi tidur maupun berdiri dengan stopper (gambar 19 step D).

Semua modul pada dasarnya dapat dikombinasikan satu dengan yang lain untuk menghasilkan beragam bentuk produk sesuai dengan kreatifitas anak. Selain itu pilihan warna juga bisa menjadi bagian dari perubahan visual seri $\mathrm{O}$ ini.

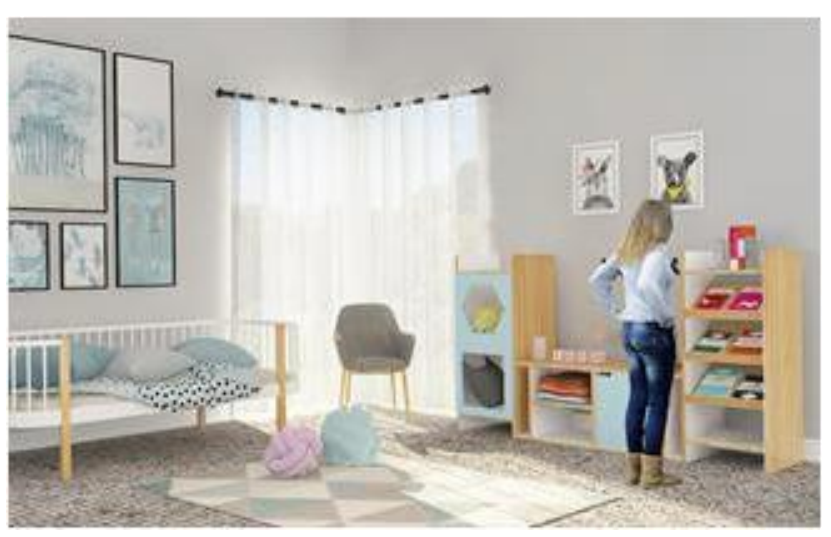

Gambar. 23. Aplikasi MOMOT seri O dalam kamar tidur anak

\section{SIMPULAN}

Anak usia 6-12 tahun berada dalam masa pertumbuhan sehingga keinginan dan kebutuhan anak juga akan terus meningkat. Guna menjembatani kebutuhan warna mebel anak pada usia 6-12 tahun maka MOMOT menggunakan warna dasar cerah (warna pastel). Sistem knockdown diaplikasikan pada perancangan ini guna membantu anak belajar mengenai konstruksi dan menstimulasi anak untuk mengolah bentuk wadah dari modul-modul yang ada. Modul dibuat dalam beberapa bentuk geometris sederhana seperti, persegi dan persegi panjang supaya mudah dipadukan satu dengan yang lain karena memiliki permukaan/sisi yang sama. Untuk memudahkan perakitan oleh anak, maka desain dibuat dengan konstruksi sederhana yaitu, mortise tenon joint, dowel, dan cross dowel, yang tidak memerlukan alat bantu khusus. Finishing yang digunakan adalah waterbased karena kandungan VOC yang rendah sehingga aman untuk anak.

\section{REFERENSI}

[1] Mcdonough, William and Michael Braungart. The Upcycle: Beyond Sustainability - Designing for Abundance. New York: North Point Press, 2013.

[2] IDEO. Design Thinking for Educator. $2^{\text {nd }}$ ed. 2012. $24 \quad$ October $2016.2<$

[3] Gibbons, Sarah. Design Thinking 101. 2016. 4 December 2016. <https://www.nngroup.com/articles/design-thinking/ >

[4] Santrock, J.W. Child Development. 14 ${ }^{\text {th }}$ ed. New York: McGraw-Hill, 2014.

[5] Wong, Donna L. Buku Ajar Keperawatan Peadiatrik. $6^{\text {th }}$ ed. Jakarta: EGC, 2009.

[6] Perhimpunan Ergonomi Indonesia. (2013). Antropometri Indonesia. 20 October 2016. <http://antropometriindonesia.org/ >

[7] Jamaludin. Pengantar Desain Mebel. Jakarta: Kiblat, 2007.

[8] Ching, Francis D.K. Interior Design Illustrated. New Jersey: John Willey \& Sons, 2002.

[9] Ching, Francis D.K. Interior Design Illustrated. New Jersey: John Willey \& Sons, 2002.

[10] UN World Commission on Environment and Development. Report of the World Commission on Environment and Development: Our Common Future. 1987. 5 December 2016. <http://www.undocuments.net/our-common-future.pdf $>$

[11] Abbott, Jessica. "What is a Carbon Footprint?." Ed. The Edinburgh Centre for Carbon Management. $2^{\text {nd }}$ ed. Eccm (February 2008). 4 December 2016. $<$ http://palletcarboncalculator.org/CarbonFootprintRe port10_logo.pdf >

[12] "Informasi Tentang Kayu Jati Belanda". Toko Jati Belanda. 2014. 4 December 2016. http://www.tokojatibelanda.com/informasi-tentangkayu-jati-belanda/ >

[13] "Finishing Kayu Jati Belanda dengan Biopolish." Biopolish. 2016. 4 December 2016. > http://www.biopolish.com/finishing-kayu-jatibelanda-dengan-biopolish-237/>

[14]"Tips Memilih Cat Furniture Anak Yang Aman." Prima Sitinurhidayah. 2016. 1 Maret 2017. <http://www.bioindustries.co.id/tips-memilih-catfurniture-anak-yang-aman-5894.html >

[15] Muharam, Agah Nugraha. Menata Furnitur di Ruang Sempit. Jakarta: Griya Kreasi. 2009.

[16] The Merriam-Webster Dictionary. $11^{\text {th }}$ ed. Springfield, MA: Merriam Webster, 2016. 